\title{
Motorcycle taxis in public transportation services within the Accra Metropolis
}

\author{
Yaw Adubofour Tuffour ${ }^{1}$, Daniel Kofi Nti Appiagyei ${ }^{2}$ \\ ${ }^{1}$ Department of Civil Engineering, Kwame Nkrumah University of Science and Technology, Kumasi, Ghana \\ ${ }^{2}$ Department of Urban Roads, Ministry of Roads and Highways, Accra, Ghana \\ Email address: \\ yat@engineer.com (Y. A. Tuffour),dknti@yahoo.com (D. K. N. Appiagyei)
}

\section{To cite this article:}

Yaw Adubofour Tuffour, Daniel Kofi Nti Appiagyei. Motorcycle Taxis in Public Transportation Services within the Accra Metropolis. American Journal of Civil Engineering. Vol. 2, No. 4, 2014, pp. 117-122. doi: 10.11648/j.ajce.20140204.12

\begin{abstract}
The Road Traffic Act (Act 683) passed in 2004 by the Parliament of Ghana precludes the use of motorcycles to carry fare-paying passengers, yet motorcycle taxi services are gradually gaining root within the public transportation sector in the Accra Metropolis, Ghana. Even though the services are not yet operated city-wide, they have begun raising public concern. This study looked at the operation and management of motorcycle taxi services in Accra and surveyed the opinions of operators, users and non-users on the services. It was established that motorcycle taxi services in the Accra Metropolis are patronized mostly by short-distance urban commuters, particularly during peak periods of traffic flow when there is heavy congestion. Patronage is gender- and age-biased as majority of patrons are male and young. Due to lack of regulation, the services tend to be concentrated along only a few routes perceived by the operators as profitable. Public opinion and acceptance of this form of public transportation are mixed. Of the 201 non-users interviewed, a slight majority (56\%) thought that the ban implicit in the Road Traffic Act on such forms of public transportation must be enforced. Most (68\%) of the patrons interviewed considered the services convenient for beating traffic congestion and safe due to the short trip lengths. Commuters who shy away from the services cited safety (46\%) and illegality of services (34\%) as their major concerns; only $4 \%$ cited the fear of falling into the hands of criminals as a concern. For the service providers, most of whom are no more than high school graduates, the taxis offer subsistence in a country where employment is hard to come by.
\end{abstract}

Keywords:Accra Metropolis, Congregation Points, Motorcycle Taxis, Public Transportation Services, Road Traffic Act

\section{Introduction}

The public transportation sector in Ghana has, for a long time, been dominated by shared taxis and low-capacity mini-buses locally known as trotros but, more recently, the scope of public transportation services in some places in the capital city (Accra) has expanded to include motorcycle taxi services. Until 2001, the use of motorcycles for commercial purposes involved only non-passenger services such as messenger services and delivery of goods. However, in 2001, motorcycle taxis emerged for the first time in Accra as an informal intervention to transport commuters from the Korleena area across a collapsed bridge on the Odaw River on Guggisberg Avenue. After the reconstruction of the bridge, the services still continued and, in time, other riders joined in and swelled the number. This genesis notwithstanding, it appears that the motorcycle taxi concept in Accra was probably motivated more by the prevalence and widespread use of such mode of public transportation in countries within the sub-region rather than the exigencies created by the collapse of the bridge. Today, motorcycle taxis provide urban public transportation services alongside those offered by trotros and shared taxis in some parts of Accra, although on a limited scale. This development is in spite of the fact that the Road Traffic Act (Act 683), passed in 2004 by the Parliament of Ghana, precludes the use of motorcycles for commercial purposes or to carry fare-paying passengers in the country.

Act 683, which prescribes a fine or a term of imprisonment or both for persons who contravene, was aimed at improving and maintaining safety for all modes of road transportation in the country. Whereas in some countries in Asia and Africa motorcycle taxis form an acceptable and integral part of public transportation, to some in Ghana, they represent a worrisome aberration that must not be allowed to entrench. Motorcycle use for personal mobility though is extensive in the northern part 
of Ghana but not as taxis.

Within the African sub-region, motorcycle taxis exist in several countries in different names, for example, okada in Nigeria, boda boda in Uganda, and zémidjan in Benin and Togo. In Ghana, the name okada has been adopted. According to Howe [1], the boda boda in Uganda has become an integral part of the transport system in that country as it is the dominant public transportation mode in many parts of the country where conventional public transportation modes find it unprofitable or unsuitable to operate. It has been noted that under certain urban and rural settings, motorcycle taxis may provide feeder services to towns or major public transport routes, offering short-distance trips [1]. However, in some countries within the West African sub-region, a substantial proportion of urban mobility needs, for example, $70 \%$ in Benin [2] and $80 \%$ in Togo [3] are actually served by motorcycle taxis. In all such places, the popularity of motorcycle taxis stems from their ability to manoeuvre urban traffic congestion and also poor road conditions that do not favour vehicular traffic [4].

It is estimated that currently there are more than 20 million motorcycle taxis in over 100 countries across the world, with the largest single concentration of over one million being in Lagos, Nigeria [5]. In Cotonou, the capital of Benin, it is estimated that about 72,000 motorcycle taxis serve a population of slightly over 700,000 residents [5]. As public transportation challenges in these places increase, so will the number and use of motorcycle taxis.

In some countries, motorcycle taxis are encouraged as they are used as a tool to address youth unemployment and mass poverty [6,7]. In Nigeria, the earnings of the majority of motorcycle taxi operators are noted to be above the minimum wage, making the sector attractive to the unemployed youth [7]. In addition, a good number of people may be engaged in the business of motorcycle repairs and maintenance [8].

One of the greatest concerns associated with the use of motorcycle for public transportation though is safety. Studies [9-12] have revealed that, on average, motorcycles have higher fatality rates than any other modes of motorized transport. In Ghana, the National Road Safety Commission reported in 2010 that more than $50 \%$ of motorcycle taxi operators in the capital city, Accra, had been involved in accident situations in one way or another with their motorcycles, with about 70\% suffering injuries [13]. In Benin, 9 out of every 10 accidents recorded in major urban centres such as Cotonou and Porto Novo, involve drivers of motorcycle taxis or zémidjans [2]. According to Miller et al. [10], motorcycles have the highest crash costs per person-mile. Also, due to the relatively long exposure to exhaust fumes, motorcycle taxi drivers have a higher risk of developing respiratory symptoms than any other group of road users [14].

Interestingly, motorcycle taxis can also be found even in advanced economies where car ownership is relatively very high and public transportation services are varied, more reliable and often of higher standards and quality than in developing countries. But they are yet to attain the growth and expansion profiles of motorcycle taxis in the developing world [5]. Anderson [15] has reported of the introduction of motorcycle taxis in New York City and Los Angeles by Moto Limos Club in an effort to help on-the-go business types navigate the chronically gridlocked streets of the two cities. Similar taxi services have been operating in Europe's busiest cities for years. In 2005, the Public Carriage Office (PCO) in Britain announced that legislation would require all licensed taxis in London to have four road wheels by March of that year [16]. This raised concerns for the motorcycle industry and users of their services [16]. In 2003, the Bristol City Council granted licenses for motorcycle taxis after consultations with police and safety experts [15]. In France, Paris Moto Taxi, Urban Driver, and other companies run motorcycle taxi services to airports, train stations and other major destinations [17].

In Ghana, the operations of motorcycle taxis have not yet become nationwide but public sentiments against the services seem to be building up gradually as there appears to be a generally low public view of the safety, security, and appropriateness of this mode of public transportation. Concerns are reinforced by occasional media reports of armed robbery attacks involving the use of motorcycles as the get-away vehicle. The expectation has been that government would act decisively and swiftly to enforce the ban on such services implicit in the Road Traffic Act (Act 683). So far, however, that has not yet happened. In a country where everything is politicized, it becomes difficult for the police to crack the whip. Occasionally though some actions are taken by the police seemingly to clamp down on the operators but tend to be short-lived and not far-reaching enough. This study looked at the operations of motorcycle taxis in Accra and sampled opinions of operators, users and non-users of the services within the metropolis.

\section{Materials and Method}

The study focused on four sub-metropolitan areas within the Accra Metropolis, namely, Ashiedu Keteke, Osu Klottey, Ablekuma South and Okaikoi South, which together constitute the Central Business District (CBD) of the metropolis and form the hub of the operations of the motorcycle taxi services. The study was designed as a field survey involving operators, users and non-users of motorcycle taxi services within the city of Accra using questionnaire administration which focused on the operation of services at the locations used by the service operators as congregation and take-off points. The congregation and take-off points were mostly major terminals and car parks, major road junctions and markets within the areas of operation. The selected congregation points were Galloway, Agbobloshie, Rawlings Park, Post Office, Tema Station, Korle Bu, Mamprobi, Kaneshie and Kwame Nkrumah Circle. These have been detailed on the map in Fig. 1. Also, consultations and interviews were held with the leadership of the operator unions and other stakeholders. 


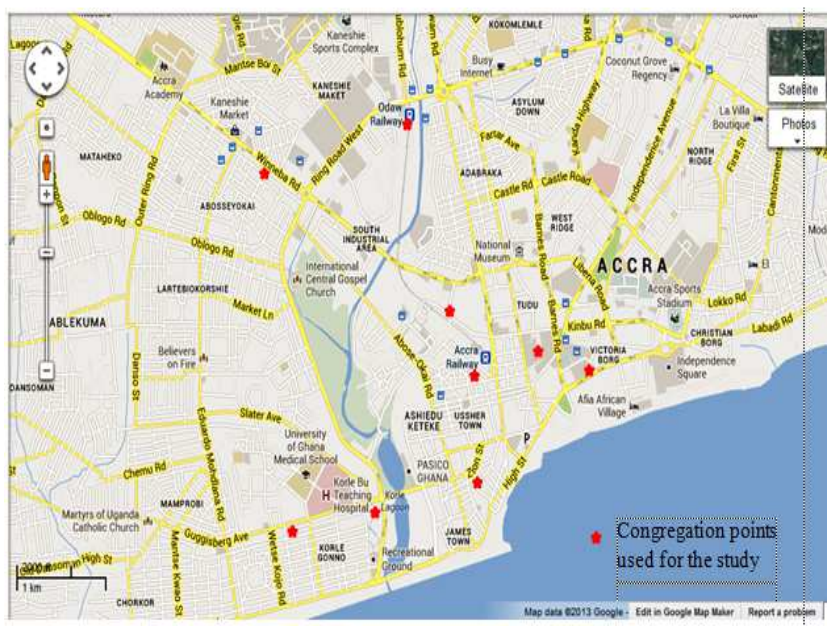

Fig 1. Locations of motorcycle taxi congregation points in Accra

\subsection{Sample Size}

Exact data on the number of riders operating at the congregation points could not be established but based on verbal information, the operator population was estimated at 225. An average of 25 operators per congregation/take-off location was, therefore, assumed. A maximum of 20 riders were selected at random for the administration of the questionnaires at each of the nine congregation points based on a list of names of the operators that was obtained. Where a selected person was not available, a replacement was made. In addition, a total of 272 persons made up of users (71) and non-users (201) of motorcycle taxi services, identified in the vicinity of the selected congregation points and willing to participate in the survey, were covered.

\subsection{Questionnaire Administration}

Two sets of questionnaires were administered; one for the operators, and the other for both users and non-users of the services. The questionnaire for the operators was in four sections; Section A was concerned with driver bio-data, Section B related to organisation and management of services, Section C related to general operations and service characteristics, and section D related to accident and safety issues. The questionnaire for both users and non-users covered socio-economic characteristics of the respondent, service demand characteristics (trip purpose, reasons for using services, and level of service), safety concerns, and users' opinions on motorcycle-based public transportation services. 3.3.4

Consultations and interviews were held with the leadership of the motorcycle taxi operator unions concerning the history and management of the services.

\section{Results and Discussion}

\subsection{Profile of Operators and Users of Motorcycle Taxis}

All the motorcycle taxi operators reached in the survey were males aged between less than 18 years and a little over 40 years; none was above 50 years. In terms of age distribution, about half $(52 \%)$ were in the age bracket 18-30 years and a little more than $10 \%$ were below 18 years. Figure 2 presents the age distribution of the drivers of motorcycle taxis in the Accra Metropolis contacted in the study.

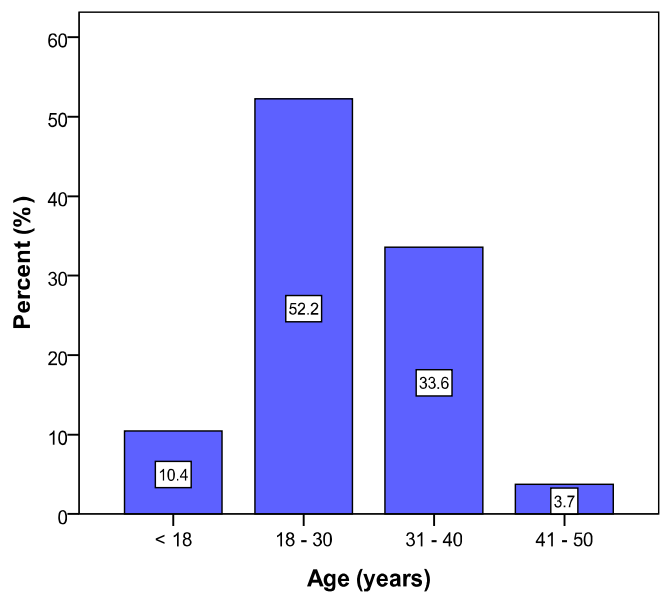

Fig 2. Age distribution of motorcycle taxi drivers

In terms of education, although about $84 \%$ of the riders interviewed said they have had some form of formal education, majority (63\%) were no more than Junior High School (JHS) graduates and only a little over $2 \%$ had tertiary education background.

Of the 272 commuters interviewed, $26 \%$ were users of motorcycle taxis with $68 \%$ being males.

This implies that male commuters have a higher propensity than their female counterparts to patronize motorcycle taxis. It was also established that the ages of most of the users were concentrated between 18 and 40 years, with close to $50 \%$ being in the $18-30$ years age bracket. This seems to suggest that elderly persons and women in particular do not consider such form of public transportation appropriate and attractive for their use.

\subsection{Organization and Management of Services}

Two operator unions were identified during the study; the Ghana Private Motorbike Operators Union (GPMOU) and the Motor Riders Association of Ghana (MRAG). Ironically, MRAG was established with government facilitation to represent the full spectrum of motorized road transport operations. Membership and registration with the unions are not compulsory for the taxi operators. That fact notwithstanding, GPMOU was noted to have active membership strength of about 180 motorcycle taxi drivers within the Accra Metropolis. Even though the unions existed, there was very little evidence of their activities and importance to the service providers other than occasionally intervening on behalf of members who got arrested by the police. But in principle, the individual drivers rather than the unions were mostly responsible for the management of 
their own activities. As a result, there was a higher concentration of taxis on routes perceived to be more commercially attractive than those that were seen as less attractive.

During the interviews, the leadership of the unions admitted that they enjoyed very little official recognition and wielded very little influence over their members; therefore, indiscipline and reckless driving among the riders were thus difficult to deal with. In effect, the rider unions existed just in name and did not appear to exercise much influence and control over the daily operations of their members.

\subsection{Operations and Service Range}

It was observed that at every loading point, the drivers maintained a loading system based on a first-come-first-served policy which was strictly respected by all. Hours of operation of services varied but most riders (75\%) began services around 6a.m. and worked between 11 and 15 hours a day. Majority (94\%) worked between five and six days a week; only about $2 \%$ worked every day. In general, most of the riders $(72 \%)$ operated from a terminal point and belonged to one operator association or another even though the associations exercised very little control over their operations. Travel information was not provided and there was no evidence of city-wide coordination of motorcycle taxi operations. On festive occasions when demand is high, the riders may engage additional drivers so as to operate morning, afternoon, and evening shifts.

Based on the responses from the respondents, it was established that about $58 \%$ of the trips made on motorcycle taxis ranged between $1 \mathrm{~km}$ and $3 \mathrm{~km}$, but a significant percentage (about $26 \%$ ) exceeded $3 \mathrm{~km}$. This means that the motorcycle taxi services are used mostly for short-distance trips within the metropolis. Apart from passenger services, the operators offer courier services, messenger services and delivery of lunches to office workers (see Fig. 3). It is evident from the figure that about half (49.3\%) of the non-passenger services are in courier services.

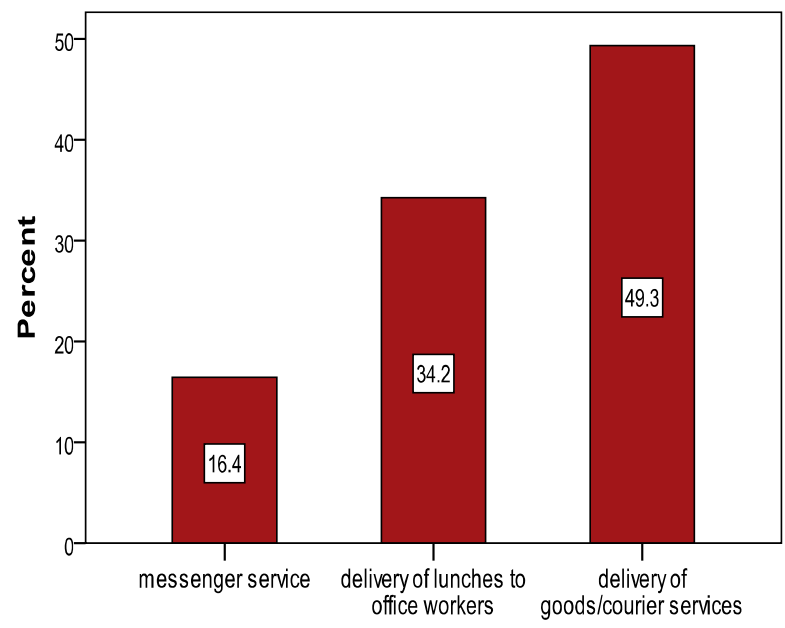

Fig 3. Non-passenger services offered by motorcycle taxis

\subsection{Usage of Services}

In terms of frequency of patronage of the taxi services, it was established that close to $82 \%$ of the user respondents said they make at least one trip daily on motorcycle taxi; about $18 \%$ avail themselves of the services once a week or less frequently. The trip frequency varied because some of the users said they accessed the services only as and when it was convenient to do so but not as their regular means of personal mobility.

Trip duration varied; $39 \%$ of the user respondents indicated that their journey times never exceeded 15 minutes while for $56 \%$ it lasted between 15 and 30 minutes. This suggests that for about $95 \%$ of the users, journey times never exceeded 30 minutes. This confirms the fact that the motorcycle taxis are being patronized mostly by short-distance urban commuters. Figure 4 shows the distribution of the major trip purposes driving commuters to use motorcycle taxis. It is clear that about $42 \%$ of the patrons use the services for the purpose of going to and returning from work.
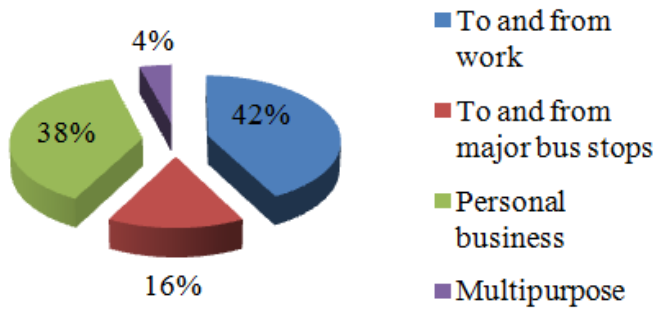

Fig 4. Purpose of motorcycle taxi usage

Though respondents were unwilling to tell which specific work they engaged in, most hinted that it had to do with making a lot of rounds within the CBD. For reasons of the flexibility of the taxi services, $38 \%$ of the users said they prefer the taxis for personal and multi-purpose business activities. Others (16\%) said they prefer to use the taxis to reach major transport terminals and other urban modes of transport primarily because of their short trip time.

In terms of the quality of services offered, about $62 \%$ of the user respondents said they were satisfied with the services and rated the level of service as high; the rest, however, rated the services as poor. In terms of user complaints about the services, $46 \%$ of the user respondents thought that over-speeding and reckless driving were issues to be addressed; others complained about the disregard for traffic rules and regulations by the drivers.

\subsection{Safety and Security Issues}

On the safety of the motorcycle taxi services, a high proportion $(72 \%)$ of the users interviewed admitted having been involved in some kind of accident situation before while using the services, though most such incidents were minor and resulted mostly from carelessness on the part of the riders while manoeuvring traffic. In spite of those accident experiences, only $41 \%$ said they felt unsafe using 
the services. Personal safety for the riders and their pillions was at an acceptable level as the study established an appreciable use $(85 \%)$ of helmets during rides. This was attributed to three major factors: 1) provision of helmets for passengers by the operators; 2) a high level of awareness of the risks associated with non-use of helmets, and; 3) possible arrest by the police for riding without a helmet.

Even though it became clear from the interview that an appreciable majority of pillions who patronized the taxi services were aware of the perception of taxis being used for robbery activities, about $83 \%$ said they had never been a victim of such criminal activities and, therefore, from that standpoint, did not have any security concerns when patronizing the services. To them, the public's concern about the lack of safety and security of motorcycle taxi services appeared overstated and the argument by opponents that the taxis could be used for criminal activities were mere perceptions that could not be backed by any empirical data. Interestingly though for the non-user respondents, only $35 \%$ rated the services as unsafe. The advocacy for non-legalization of motorcycle taxis on the presumption that they could be used for criminal activities did not appear to be strongly supported even by the non-users as surprisingly only $2 \%$ admitted that their non-patronage was related to crime. Rather, about $19 \%$ of the non-users did not favour motorcycle taxis simply because of reckless driving on the part of the riders.

\subsection{Legalization of Motorcycle Taxi Services}

Of the 201 non-user respondents interviewed, 56\% said government should show greater commitment to enforcing the ban on the operations of motorcycle taxis; but others expressed opinion that restructuring could help enhance the image of the services and win public confidence in the taxis as an acceptable form of public transportation. In spite of that, $66 \%$ still maintained that they would not patronize motorcycle taxis for whatever reason even if the services were to be restructured and legalized. In the case of the user respondents, about $83 \%$ admitted being aware that operation of motorcycle taxi services is illegal in the country but thought legalization was necessary to recognize and accept motorcycle taxis as a means of public transportation.

\section{Conclusion}

Within the past decade or so, the use of motorcycles for public transportation services in the form of motorcycle taxis has gained prominence in certain parts of the Accra Metropolis, Ghana. This is notwithstanding the fact that the Road Traffic Act (Act 683) passed in 2004 by the Parliament of Ghana prohibits the use of motorcycles for commercial purposes or to carry fare-paying passengers. Whereas motorcycle taxis are an acceptable form of public transportation mode in some of the countries within the sub-region and in many parts of the world, they are yet to find favour with the generality of Ghanaians. The services are patronized mostly by urban commuters for short distances which rarely exceed $3 \mathrm{~km}$, particularly during peak periods of traffic flow when congestion is very high. Patronage is gender- and age-biased as majority of the users are male and young. A slight majority (58\%) of non-users interviewed thought that the ban implicit in the Road Traffic Act on such forms of public transportation must be enforced. However, most (68\%) of the patrons interviewed considered the services convenient for beating traffic congestion and safe. Non-users of the services cited safety and illegality of services as their major concerns. Most of the service operators belong to one or the other of two rider associations identified, but the associations appeared to wield very little control over the activities of the operators. For the service providers, most of whom are no more than high school graduates, the taxis offer subsistence in a country where employment is hard to come by.

\section{References}

[1] J. Howe. 'Filling the middle': Uganda's appropriate transport services. Transport Reviews, 23(2), 2003, 161-176.

[2] G. M. J. Boko. "Air pollution and respiratory diseases in African big cities", Proc. $3^{\text {rd }}$ Int. Conf. on Environment and Health, Dec. 15-17, 2003, Chennai, India pp. 32-43.

[3] E. M. Assamoi and C. Liousse. A new inventory for two-wheel vehicle emissions in West Africa for 2002. Atmospheric Environment, Vol. 44, Issue 32, 2010, pp. 3985-3996.

[4] M. Sohail, D. A. C. Maunder, and S. Cavill. Effective regulation for sustainable public transport in developing countries. Transport Policy 13, 2006, pp. 177-190.

[5] World Moto, http://www.worldmoto.com/about-industry.php. Accessed August 17, 2014.

[6] G. M. M. Nyachieo. Creating Employment through Transport; the Youth and Motorcycle (Boda Boda) in Kitengela, Kajiado County-Kenya, Research Journal in Organizational Psychology and Educational Studies (RJOPES), Vo. 2, No. 4, July, 2013.

[7] O. Olurinola. Informal Self-Employment and Poverty Alleviation: Empirical Evidence from Motorcycle Taxi Riders in Nigeria. International Journal of Economics and Finance, Vol. 3, No. 2, May, 2011

[8] R. Cervero and A. Golub. Informal Transport: A global perspective. Transport Policy, 14(6), 2007, pp. 445-457.

[9] E. O. Odelowo. "Pattern of trauma resulting from motorcycle accidents in Nigerians: a two-year prospective study," African Journal of Medicine \& Medical Sciences, 23.2, 1994, pp. 109-12.

[10] T. R. Miller, R. S. Spicer, D. C. Lestina, and D. T. Levy. Is it safest to travel by bicycle, car, or big truck? Journal of Crash Prevention and Injury Control, 1(1), 1999, pp. 25-34.

[11] K. S. Oluwadiya, L. M. Oginni, A. A. Olasinde, and S. O. Fadiora. "Motorcycle limb injuries in a developing country", West African Journal of Medicine, 2004, Jan.-March 23 (1): 42-47. 
[12] B. A. Solagberu, C. K. P. Ofoegbu, A. A. Nasir, O. K. Ogundipe, A. O. Adekanye, and L. O. Abdur-Rahman. Motorcycle injuries in a developing country and the vulnerability of riders, passengers, and pedestrians. Injury Prevention, Vol. 12, Issue 4, 2006, pp. 266-268.

[13] National Road Safety Commission. The use of motorcycles for transporting passengers for hire and reward in Ghana (2004-2006). Accra, 2010.

[14] F. Messan, M. Lawani, B. Akplogan, P. Dansou, D. Mama, R. Hounkponou, and R. Dagnitché. "Bronchospasm Diagnosis in Motorcycle Taxi Drivers Exposed to Automotive Pollutants in Porto-Novo," Open Journal of Respiratory Diseases, Vol. 3, No. 1, 2013, pp. 13-20. doi: 10.4236/ojrd.2013.31003.
[15] A. Anderson. "First motorcycle taxi service headed for Los Angeles and New York." http://www.autoblog.com/2011/04/15/first-motorcycle-taxi-s ervice-headed-for-los-angeles-and-new-yor/. Accessed August 20, 2014.

[16] T. Harkness. "Motorcycle taxis face ban." The Telegraph, Wednesday May 25, 2011, London. http://www.telegraph.co.uk/motoring/motorbikes/2732923/ Motorcycle-taxis-face-ban.html. Accessed August 20, 2014.

[17] Motorbike Taxi in Paris and suburbs. http://www.urban-driver.com/english.php. Accessed August 20, 2014. 